\title{
Seismic Behavior of Large-Span Open-Web Floors Consisting of I-Shaped Steel Chords and Steel Tube Webs
}

\author{
Li Zhou $\mathbb{D}^{1,2}$, Yong Huang $\left(\mathbb{D},{ }^{1}\right.$ Bo Chen, ${ }^{1}$ Song $\mathrm{Hu}^{3}$ and Chenyun Zhang ${ }^{1}$ \\ ${ }^{1}$ College of Architecture and Urban Planning, Guizhou University, Guiyang 550003, China \\ ${ }^{2}$ Innovation Center of Safety \& Protection of Structures, ZJKJ Corp, Guiyang 550018, China \\ ${ }^{3}$ College of Civil Engineering, Guizhou University, Guiyang 550003, China \\ Correspondence should be addressed to Yong Huang; gzuhuangy@163.com
}

Received 4 June 2020; Revised 4 October 2020; Accepted 6 October 2020; Published 21 October 2020

Academic Editor: Mehmet Serkan KIRGIZ

Copyright ( 92020 Li Zhou et al. This is an open access article distributed under the Creative Commons Attribution License, which permits unrestricted use, distribution, and reproduction in any medium, provided the original work is properly cited.

\begin{abstract}
A composite large-span open-web floor (COF) system is introduced in this paper, which is composed of I-shaped steel chords, steel tube webs, and concrete slabs. One COF specimen was fabricated and tested under cyclic loadings. The failure process and hysteretic curve of the specimen were discussed in detail. Moreover, a finite element (FE) model was developed and verified by experimental results. A parametric study was performed to examine the effects of the concrete strength, steel strength, section steel thickness, and structural height. The parametric study demonstrates that the effects of the steel strength, section steel thickness, and structural height on the load-displacement hysteretic curve are proved to be significant. As for the bearing capacity and stiffness degradation of the COF system, the influence of the steel strength and section steel thickness is stronger than that of the concrete strength and structural height. Additionally, it is also found that the influence of the steel strength and section steel thickness on the energy dissipation is remarkable; the energy dissipation ability of the structure decreased with increasing the steel strength and increased with increasing the thickness of section steels.
\end{abstract}

\section{Introduction}

Large-span floor system has been used increasingly in many structural applications including exhibition halls, airport terminals, railway stations, and other large public buildings. At present, two of the most commonly used floor types in this kind of building are the reinforced concrete beam-plate floor system and the steel structural floor system. However, the disadvantages of those floor systems are obvious, such as heavy weight, low stiffness, large section size, and poor seismic performance. Thus, looking for a better structural scheme of large-span floor system is essential for large-span buildings.

Over the past few decades, steel-concrete composite structures have been a very popular selection in practical engineering, owing to the excellent structural behavior in terms of high bearing capacity, low weight, high ductility, high stiffness, and full usage of construction materials. So far, the structural behavior of the composite members, connections, and frames was detailedly investigated by researchers [1-5]. In the field of steel-concrete composite large-span floor system, Brattland and Kennedy focused on the flexural behavior of steel trusses with concrete slabs and presented the experimental results and analysis of two fullscale test specimens. Test results showed that ductile behavior up to failure can be obtained without failure of the web members. It also proved that steel trusses acting compositely with concrete slabs on wide rib profile steel deck are an economical system for long-span floors [6]. Huang et al. investigated an innovative composite open-web floor, which consists of concrete slabs, steel webs, and I-shaped steel chords. The safety and reliability of the structure were verified by a field test, and the design method was proposed by theoretical analysis. The results of test and analysis showed that the composite floors have the advantages of high stiffness, strong bearing capacity, and low steel consumption [7]. Merryfield et al. studied the influence of connection types in the composite floor system; the system 
consists of concrete slabs, corrugated metal deck sheets, and open-web steel joists. Two full-scale specimens were designed, and the connection type of Puddle welds and Hilti screws were used for each specimen, respectively. Both two specimens were tested until failure under different combinations of static and fatigue load cycles. The test results showed that significant composite action is developed using puddle-weld shear connectors [8]. Luan et al. proposed an innovative steel open-web floor system, in which the top and bottom T-shaped steel chords are connected by a steel square tube, as the support of the top concrete slabs. Then, a fullscale flexural test was conducted to evaluate the flexural performance and failure mechanisms of the structures. It was concluded that the steel open-web floor system presents advantages of high large-span capability, low material cost, and fast construction [9]. Yang et al. proposed an innovative flat steel plate-concrete composite slab, in which the flat steel plate and the concrete slabs are connected by perfobond shear connectors. Six specimens were loaded with symmetric two-point load at a quarter of the length. The test results showed that the composite slabs have a good mechanical performance with high bending capacity, substantial flexural rigidity, and good ductility [10]. Luo and Zhang presented an experimental and analytical study on the flexural response of a steel-concrete composite truss beam. The effects of the shear connectors' configuration on the flexural response of the composite trusses were examined. It was found that composite truss beams failed via the yielding of the bottom chords, which exhibited ductile behavior [11]. Lorenc focused on clothoid-shaped composite dowels of large-span composite beams in bridge system and presented experimental and numerical investigations on mechanical mechanism of this kind of dowel. It was found that the behavior of the clothoidal dowel strongly depended on the anchorage of its upper part in the concrete body $[12,13]$. Besides, Zhang et al. studied the vibration performance of an innovative large-span U-shaped steel-concrete composite hollow waffle slab. The research results of field testing and theoretical analysis showed that larger vibration happens along the long span with the same distance from the central floor [14].

Recently, a composite large-span open-web floor system consisting of I-shaped steel chords and steel tube webs (COF: composite open-web floor) was applied in actual projects, as shown in Figure 1. It is noteworthy that the COF systems have exhibited good economic advantages under conditions of large spans and heavy loads, which has attracted the interest of many structural engineers and researchers. Figure 2 shows the details of the composite floor system, in which the bottom I-shaped steel chords are connected by a steel square tube, and cross connectors are welded on the inside of steel square tube for connecting the webs of I-shaped steels. On the top and bottom of the steel tube, steel plates are welded to the steel tube, which is used for connecting the flanges of I-shaped steels and providing a welding site for cheese head studs, respectively. After fabricating the steel skeletons, the reinforcement meshes are arranged on the top of the steel skeletons. Finally, the concrete pouring is completed.
For the COF system, the primary advantages can be summarized as follows:

(1) The COF system has characteristics of large span, high structural stiffness, and low structural thickness

(2) The space between the bottom chords and the top slabs can accommodate ducts and pipes without compromising the story net height

(3) The material consumption and structural weight of COF system are lower than the traditional floor system owing to the open-web formation

In the previous study, most of research works were focused on the static behavior of the COF system [7]. Nevertheless, the research information on seismic behavior of this kind of floor system is still limited currently. It should be noted that the large-span structure has some special dynamic characteristics, such as dense characteristic frequencies and numerous vertical vibration modes $[15,16]$. Therefore, long-span structures are sensitive to seismic effects, especially vertical earthquakes. Some studies showed that the vertical ground motions cause significant amplification in the moment demands of large-span horizontal members, and the dynamic response induced by vertical acceleration is much larger than the effect of dead load [17]. Moreover, the research on horizontal seismic response of large-span floors also identified that significant vertical acceleration and displacement responses can be induced by horizontal seismic excitation, which leads to an amplification of the vertical action effect of the structure [16]. To promote the application of the COF system in practical engineering, especially in high earthquake intensity regions, it is necessary to conduct in-depth investigations on the seismic behavior of the COF system. Therefore, this paper presents the results of seismic research on the COF system; the hysteretic behavior, failure mode, strength and stiffness degradation, structural ductility, and energy dissipation capacity of the COF system were analyzed. The results of this work can provide references for applications of the COF system in seismic regions.

\section{Test Model for Verification}

2.1. Test Model Description. To investigate the seismic behavior of COF systems and provide verification data for FE simulations, one test specimen was designed and fabricated. The dimensions of the COF specimen are plotted in Figure 3, in which, the side length of the square steel tube is $50 \mathrm{~mm}$, the width of the flange and the web of the I-shaped steel is $30 \mathrm{~mm}$, and the dimensions of steel plates welded on the top and bottom of the steel tube are $90 \mathrm{~mm} \times 90 \mathrm{~mm}$. For all shaped steel components, the wall thickness is $2 \mathrm{~mm}$. In each connection joint, eight $M 5 \times 30$-grade cheese head studs are welded to the top surface of the steel plate. The diameter and length of the cheese head stud are $5 \mathrm{~mm}$ and $30 \mathrm{~mm}$, respectively.

Carbon structural steel Q235 was used for fabricating the bottom I-shaped steel chords, steel tube webs, and steel plates. The mechanical properties of steel were tested 
according to the standard GB/T 228-2002 [18]; the values of the yield strength $\left(f_{\mathrm{y}}\right)$ and elastic modulus $\left(E_{\mathrm{s}}\right)$ are $241 \mathrm{MPa}$ and $215 \mathrm{GPa}$, respectively. Steel bars with the diameter of $4 \mathrm{~mm}$ were used as reinforcement meshes spaced by $40 \mathrm{~mm}$. The tested yield stress and the elastic modulus of the steel bar are $255 \mathrm{MPa}$ and $208 \mathrm{GPa}$, respectively. Besides, the yield strength of the cheese head stud is $400 \mathrm{MPa}$.

Fine aggregate concrete with the grade of $\mathrm{C} 25$ was used for the top slabs. Portland PO32.5 cement, river sand with a fineness modulus of 2.8 , and fine gravel with a maximum size of $5 \mathrm{~mm}$ were used for the preparation of concrete. The mix proportion is listed in Table 1 .

The concrete properties were tested according to standard GB/T 50081-2016 [19], the average cubic compressive strength $f_{\mathrm{cu}}$ is $26.2 \mathrm{MPa}$ (cube size: $150 \mathrm{~mm} \times 150 \mathrm{~mm} \times 150 \mathrm{~mm}$ ), and the Young modulus is $27.7 \mathrm{GPa}$ (prism size: $150 \mathrm{~mm} \times 150 \mathrm{~mm} \times 300 \mathrm{~mm}$ ). Besides, the axial compressive strength $f_{\mathrm{c}}$ and tensile strength $f_{\mathrm{t}}$ are converted according to GB 50010-2010 [24]. The values of $f_{\mathrm{c}}$ and $f_{\mathrm{t}}$ are $17.5 \mathrm{MPa}$ and $1.84 \mathrm{MPa}$, respectively.

2.2. Test Setup and Loading History. Figure 4 shows the test site of the COF specimen. First, two concrete abutments were fastened to the strong floor through steel anchors. Then, the specimen was installed on the top of the abutments using steel bolts. Finally, the load distribution beam was fixed on the top of the specimen and connected to the hydraulic actuator.

During the test, vertical cyclic loads were applied to the test specimen to simulate earthquake action. The complete process for vertical loading was divided into force control and displacement control stages in accordance with the cyclic seismic testing guidelines of ATC-24 [20], as shown in Figure 5. During the force control loading stage, a single cycle was applied to the specimen at each of the following force levels: $0.25 P y, 0.50 P y, 0.75 P y$, and $1.0 P y$, where $P y$ is the yield force estimated from the FE analysis. When the specimen entered the yield state, the displacement control mode was adopted for loading. Three cycles were exerted at the integer multiple of $\Delta y$, where $\Delta y$ is the estimated yield displacement corresponding to $P y$.

2.3. Failure and Hysteretic Curve. During the initial stage of loading, no obvious cracks of the testing specimen were visually observed, and the specimen was still in elastic state. When the vertical tensile load was increased to approximately $10 \mathrm{kN}$, bending cracks were observed on the upper surface of the middle span of the concrete slab, and the crack width was approximately $0.2 \mathrm{~mm}$. Thereafter, some new bending cracks were observed at the midspan of the concrete slab, and the existing cracks continued propagating accompanied by the increasing vertical load. When the vertical load increased to $20 \mathrm{kN}$, slight slip was observed between the steel tube webs and the concrete slab at the end of the specimen, which showed that the shear force of steel tube webs was relatively large. When the applied load reached about $30 \mathrm{kN}$, the maximum crack width was approximately
$1.2 \mathrm{~mm}$, and the bearing capacity of the specimen decreased significantly with the increase of loading cycles. Finally, bending damage of the concrete slab and slip between steel tube webs and concrete slab led to the failure of the specimen.

Figure 6 shows the load-displacement hysteretic curves of the COF specimen. It is illustrated in Figure 6 that the hysteretic curves presented the straight line shape without distinct loops at the beginning of the loading, which indicated that the specimen was in elastic state. Accompanied with the increase of the applied load, the load-displacement hysteretic curves gradually had nonlinear characteristics, and the residual deformation generated when unloading. After yielding of the COF specimen, the tensile and compressive hysteretic curves showed a significant difference. When the specimen was under tensile loading, the applied load increased slowly, and the residual deformation was huge. When the specimen was under compressive loading, the applied load was rapidly increased, and the residual deformation was relatively small.

\section{Finite Element Models}

3.1. General Description. The Dassault Systèmes SIMULIA Corp. developed a widely used finite element analysis (FEA) software for simulating the nonlinear behavior of structures, which is called ABAQUS [21]. Many scholars investigated the nonlinear behavior of steel-concrete composite structures using ABAQUS, where the predicted results by ABAQUS matched well with the experimental results $[22,23]$. In this study, the software ABAQUS was adopted to investigate the mechanical behavior of COF systems and conduct a parameter study on the aspect of seismic performance.

3.2. Constitutive Models for Materials. The bilinear kinematic hardening model with a von Mises yield criterion and an associated plastic flow rule of steel was used to simulate the behavior of the steel materials. The hardening modulus of the steel was assumed to be $0.01 E s$, where $E s$ is the elastic modulus of the steel. Figure 7 shows the stress-strain relationship for steel materials. As for concrete, the constitutive model recommended by GB 50010-2010 [24] was adopted, and the stress versus strain relationship of the concrete is shown in Figure 8.

3.3. Element Types and Meshes. In the finite element (FE) model, eight-node reduced integral format 3D solid element (C3D8R) was used to simulate the concrete slab, four-node shell element (S4R) was used to simulate the I-shaped steels and steel tubes, and two-node truss element (T3D2) was employed to simulate the reinforcement meshes and cheese head studs. During the assembly of the FE components, cheese head studs and steel plates were connected by using the "coupling region" function, and all degrees of freedoms were constrained. A surface-to-surface contact interaction was employed at the surfaces of the steel plate and the concrete slab, the normal behavior was defined as "hard 
contact," and the tangential friction coefficient was taken as 0.45 [25]. Finally, the reinforcement meshes and cheese head studs were embedded in the concrete slab using the "embedded region" function. In addition, the element size should be considered for satisfying a good accuracy and a reasonable computational time. In order to get a reasonable mesh size, precalculation was conducted for the COF system. It was found that a mesh size of $15 \mathrm{~mm}$ for the whole model can get better results in simulation. Figure 9 shows the typical component meshes for the COF specimen.

3.4. Verification of the Numerical Model. To verify the validity of the numerical model, $P-\Delta$ skeleton curve of the COF system calculated by the above FE model was compared with the tested curve, as shown in Figure 10. It can be seen that the elastic stiffness of the FE model is almost as same as that of the test specimen. During the later stage of loading, the two curves presented some differences. Compared with the test results, the loading values of the FE model are slightly larger in negative loading and slightly smaller in positive loading. On the whole, reasonable accuracy has been achieved for the FE model in predicting the structural response of the COF system.

\section{Analytical Results of FE Models}

4.1. Description of FE Models. To further investigate the seismic behavior of the COF system, several FE models with different parameters were modeled and calculated. Among them, the basic model was named as COF-1, and the information of the model was described as follows:

(1) The dimensions and details of the basic model are the same as the test specimen, as illustrated in Figure 3

(2) The concrete grade of the top plate is $\mathrm{C} 30$, and the corresponding axial compressive strength $f_{\mathrm{ck}}$ is 20.1 $\mathrm{MPa}$

(3) The steel grades of the I-shaped steel, steel tube, and connecting plate are Q235, and the corresponding yield strength $f_{\mathrm{y}}$ is $235 \mathrm{MPa}$

(4) The clearance between concrete slab and I-shaped steel chord is $42 \mathrm{~mm}$, and the total height of the COF system is $110 \mathrm{~mm}$

(5) The thickness of I-shaped steels, steel tubes, and connecting plates is $2 \mathrm{~mm}$, and the section sizes of all section steel components are the same as those of the test specimen

As for other FE models, COF-1, 2, and 3 are adopted to investigate the effects of concrete strength on the seismic behavior of the COF system; the only difference among the three is the concrete grade of the top plate. The concrete grades of COF-2 and 3 are C35 and C40, respectively, and the corresponding axial compressive strengths are $23.4 \mathrm{MPa}$ and 26.8 MPa. COF- 4 and 5 are the same as COF-1 except for the steel grade of section steels. Q345 and Q420 are used for the section steels of COF-4 and COF-5, respectively, and the yield strengths are $345 \mathrm{MPa}$ and $420 \mathrm{MPa}$, respectively. Compared with COF-1, only the section steel thickness of COF- 6 and 7 is different; steel plate with a thickness of $1.5 \mathrm{~mm}$ and $2.5 \mathrm{~mm}$ are used for COF-6 and 7, respectively. The only difference among COF-1, 8 , and 9 is the clearance between the concrete slab and I-shaped steel chords; the clearance values of COF-8 and 9 are $22 \mathrm{~mm}$ and $62 \mathrm{~mm}$, respectively; namely, the total heights of COF- 8 and 9 are $90 \mathrm{~mm}$ and $130 \mathrm{~mm}$, respectively.

4.2. Failure Process Analysis. Figure 11 shows the stress development process of components of the COF-1 model; the values were picked up from spots with maximum stress. For steel components, the type of von Mises stress was selected to reflect their stress changement; for concrete slab, the type of stress S33 was selected to reflect its stress development process. With the displacement of midspan increased to $+3.1 \mathrm{~mm}$ in the negative direction, the stress S33 of concrete slab was approximately $2.1 \mathrm{MPa}$, exceeding its cracking strength. Accompanied by the increasing displacement, the steel stress and concrete compressive stress kept increasing. When the vertical displacement increased to $+9.6 \mathrm{~mm}$ in the negative direction, the von Mises stress values of the I-shaped steel, steel tube, and reinforcement meshes are approximately $235 \mathrm{MPa}$, reaching their yield strength. It was also found that the I-shaped steel and steel tube would be yielded at the displacement of $-9.6 \mathrm{~mm}$ whereas the reinforcement meshes would not. With the vertical displacement increased to $-16.4 \mathrm{~mm}$ in the positive direction, the reinforcement meshes reached its yield strength. Thereafter, the von Mises stress values of the I-shaped steel and steel tube increased very slowly with the further increase in the vertical displacement. When the vertical displacement reached approximately $-24.5 \mathrm{~mm}$, the stress S33 of concrete slab was approximately $-20.1 \mathrm{MPa}$, reaching its axial compressive strength, which means the concrete was crushed. After that, the stress values of the concrete slab and reinforcement meshes decreased quickly owing to the concrete crushing on the top slab.

Figure 12 shows the stress states of all components under vertical deflection of $-10.8 \mathrm{~mm}$. It can be seen that the structural response of the COF system is remarkable at the locations of the support and midspan. For the top reinforced concrete slab, the phenomenon of stress concentration mainly occurs in the position where the steel tube connects to the concrete slab. For the steel tube, the closer the position to midspan, the smaller the stress value of the steel tube. As for the bottom I-shaped steel chords, the bottom flanges of the chords at the locations of the support and midspan have a greater stress.

4.3. $P-\Delta$ Hysteretic Curves. The $P-\Delta$ hysteretic curves of all FE models are shown in Figure 13. It is evident from Figure 13 that the hysteretic curves presented the straight line shape at the beginning of the loading. Accompanied by the increasing displacement, the hysteretic curves presented the shuttle shape, and the shape of hysteretic curves became increasingly plump. On the whole, the curves of all FE models are smooth and full, with no obvious pinching phenomena. 


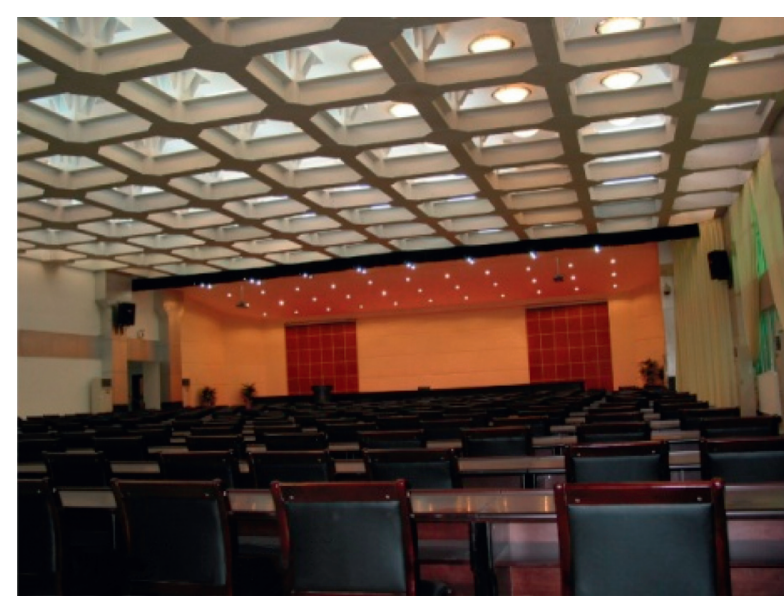

(a)

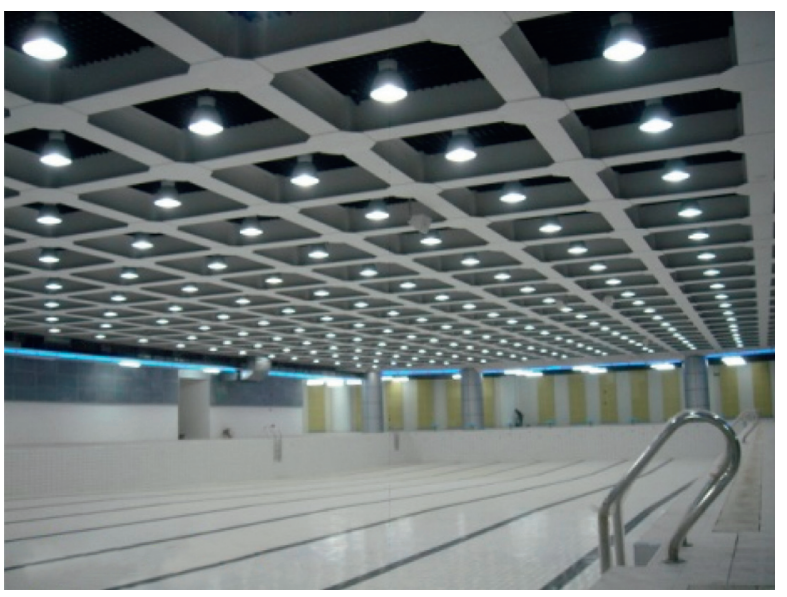

(b)

FIgure 1: Applications of COF in practical projects. (a) Conference hall. (b) Natatorium.

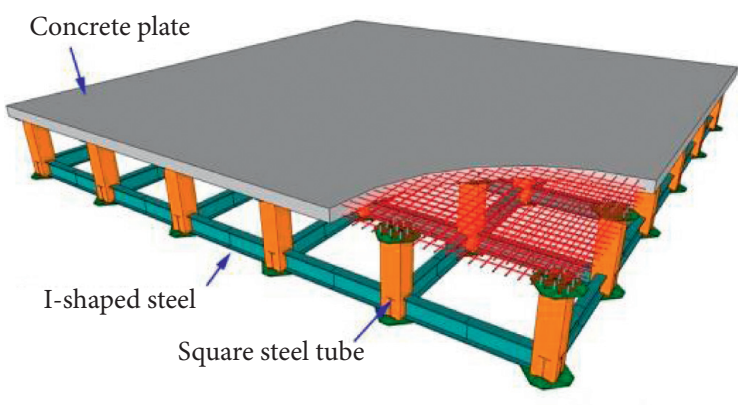

(a)

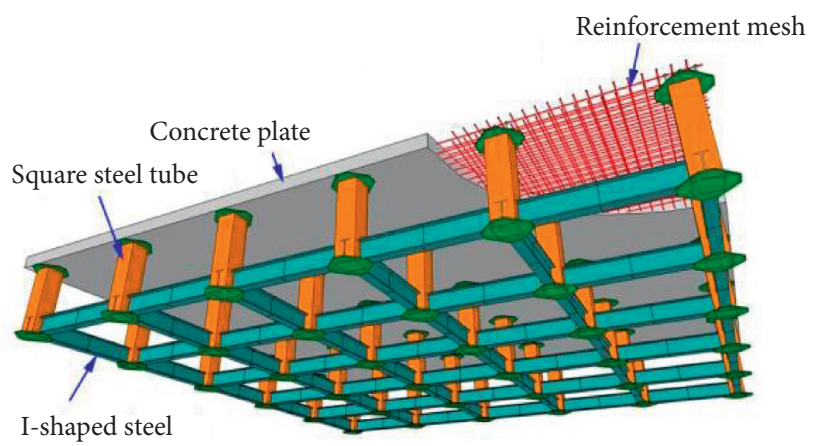

(b)

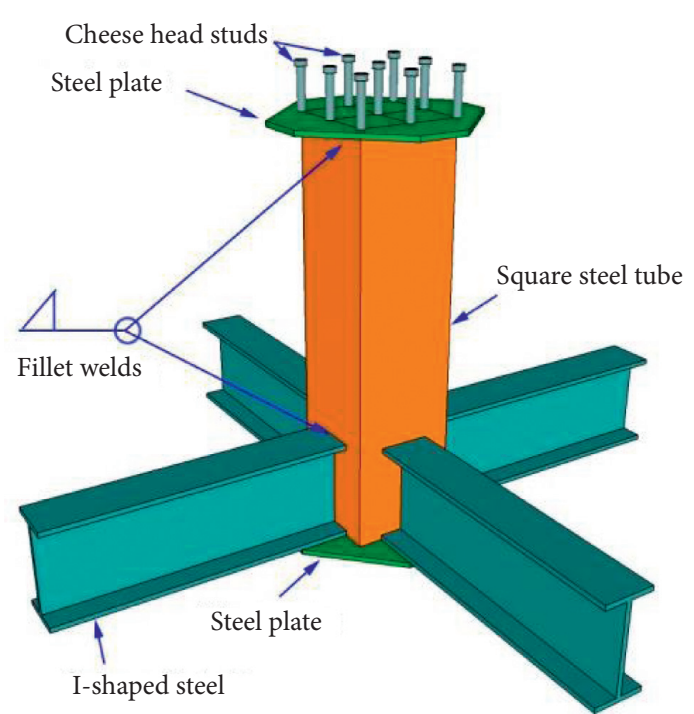

(c)

Figure 2: Details of composite floor system. (a) Overhead view. (b) Upward view. (c) Schematic view of joint.

For models with different parameters, the hysteretic curves presented certain differences. Comparison of models COF-1, COF-2, and COF-3 indicated that an increase in concrete strength caused no significant change in hysteretic curves, while it created a certain influence in structural bearing capacity. Comparison of models COF-1, COF-4, and COF-5 indicated that an increase in steel strength improved the bearing capacity of the COF system, but reduced the plumpness of the curves. Comparison of models COF-1, COF-6, and COF-7 indicated that an increase in the thickness of the section steel improved the bearing capacity of the COF system and increased the areas of the hysteretic loops. Furthermore, comparison of models COF-1, COF-8, and COF-9 indicated that an increase in the clearance between concrete slab and I-shaped steel chord (an increase in the total height of the COF system) improved the bearing capacity of the COF system, but it seems that the area growth of the hysteretic loops is limited.

4.4. Bearing Capacity. To evaluate the bearing capacity of COF systems with different parameters, the applied loads at displacements of $\pm 10.8 \mathrm{~mm}$ were taken as the bearing capacities of the structure. The reason of such choice is that the 


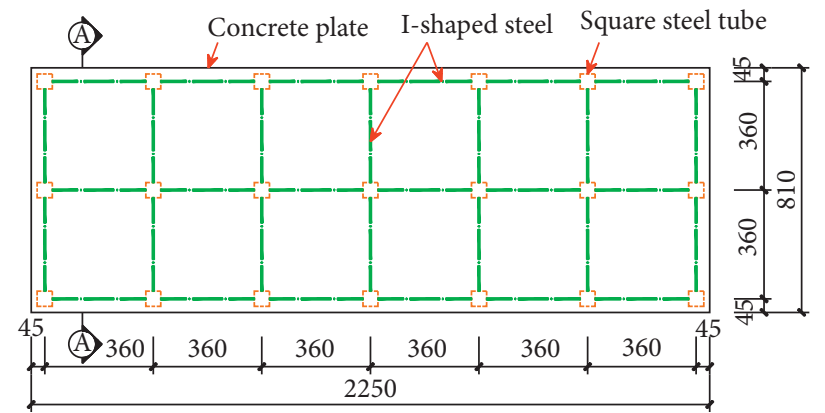

(a)

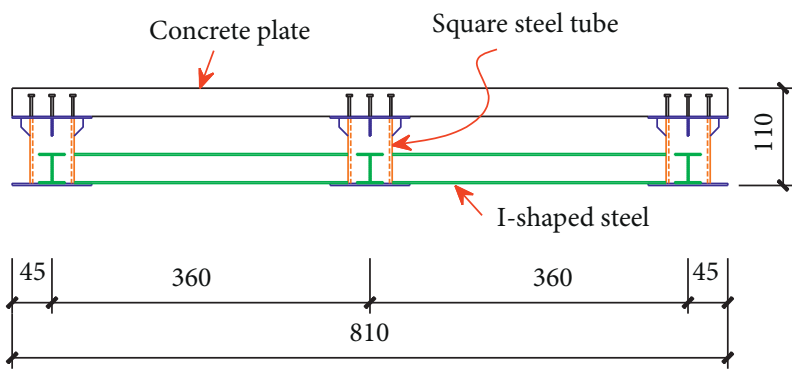

(b)

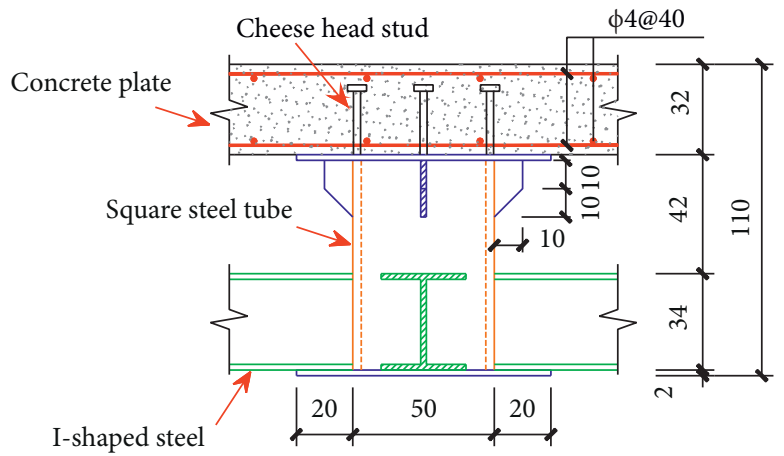

(c)

Figure 3: Dimensions of COF test specimen. (a) Floor plan of specimen. (b) A-A section. (c) Details of joint.

TABLE 1: Mix proportion of concrete.

\begin{tabular}{lccc}
\hline Cement $\left(\mathrm{kg} / \mathrm{m}^{3}\right)$ & Water $\left(\mathrm{kg} / \mathrm{m}^{3}\right)$ & River sand $\left(\mathrm{kg} / \mathrm{m}^{3}\right)$ & Fine aggregate $(5 \mathrm{~mm})\left(\mathrm{kg} / \mathrm{m}^{3}\right)$ \\
\hline 400 & 175 & 565 & 1260
\end{tabular}

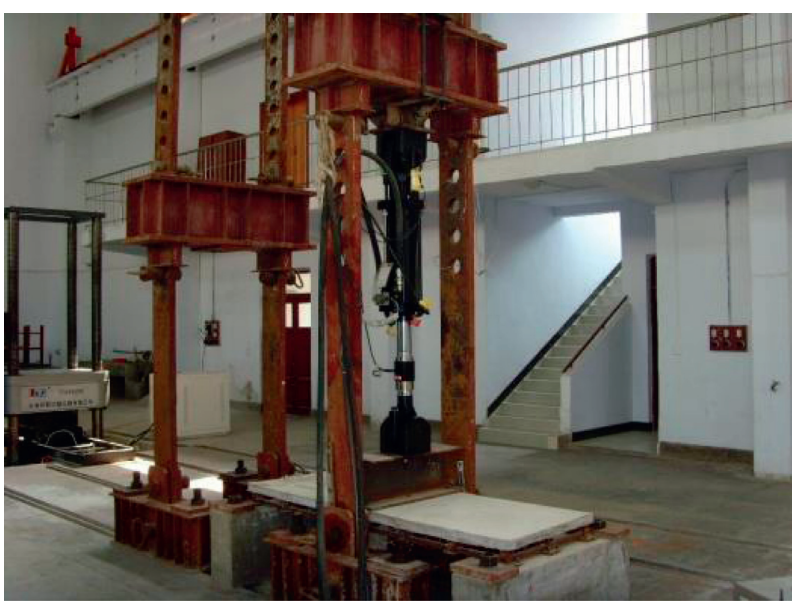

FiguRE 4: Test setup photograph.

displacements of $\pm 10.8 \mathrm{~mm}$ are about $1 / 200$ of the structural span length, which are the limit values for normal use of structures. Figure 14 shows the comparison on the bearing capacity of different COF systems. It can be seen that the bearing capacities of structures in the negative direction are smaller than those in the positive direction. For the structure with different concrete grades, when the axial compressive strength of concrete increases from $20.1 \mathrm{MPa}$ to $23.4 \mathrm{MPa}$, 26.8 $\mathrm{MPa}$, the bearing capacity in the positive direction is found to increase by $5.7 \%$ and $9.3 \%$, respectively; the bearing 


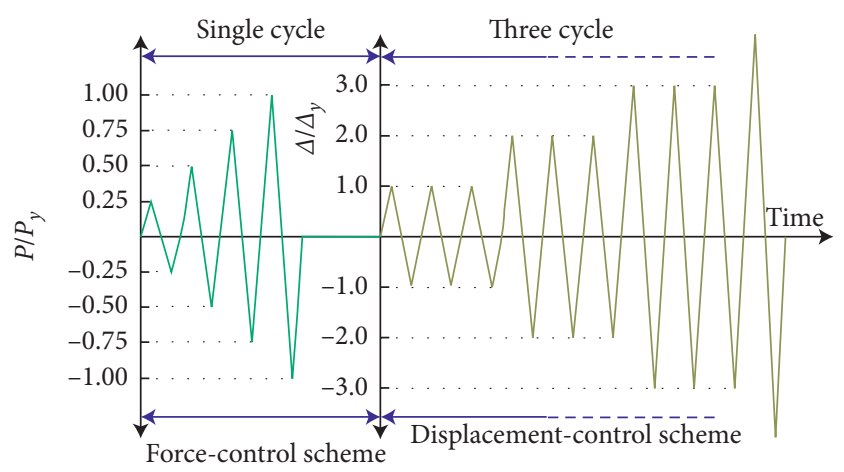

FIgURE 5: Loading history.

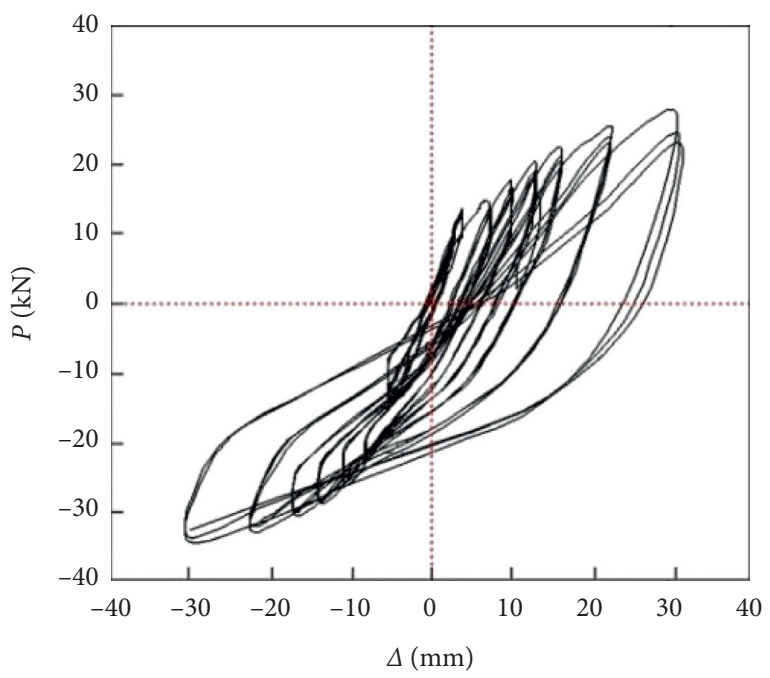

FIgURE 6: Hysteretic curves of the specimen.

capacity in the negative direction is found to increase by $0.4 \%$ and $4.4 \%$, respectively. Thus, it can be seen that the concrete grade has little impact on the bearing capacity of the structure. The steel grade has a great impact on the bearing capacities of the COF systems, especially for the bearing capacities in the positive direction, as seen in Figure 14(b). When the yield strength of section steels increases from $235 \mathrm{MPa}$ to $345 \mathrm{MPa}, 420 \mathrm{MPa}$, the bearing capacity in the positive direction is found to increase by $13.5 \%$ and $18.5 \%$, respectively; the bearing capacity in the negative direction is found to increase by $1.6 \%$ and $6.7 \%$, respectively. Figure 14(c) shows the effects of the section steel thickness on the bearing capacities of COF systems. The comparisons of the bearing capacities show that the section steel thickness has a remarkable effect on the bearing capacities. When the thickness of section steels increases from $1.5 \mathrm{~mm}$ to $2.0 \mathrm{~mm}, 2.5 \mathrm{~mm}$, the bearing capacity in the positive direction is found to increase by $14.7 \%$ and $43.7 \%$, respectively; the bearing capacity in the negative direction is found to increase by $24.8 \%$ and $47.5 \%$, respectively.

Figure 14(d) shows the comparisons of the bearing capacities of COF systems with different structural heights; the clearance between the concrete slab and I-shaped steel chords for COF-1, COF-8, and COF-9 is $22 \mathrm{~mm}, 42 \mathrm{~mm}$, and $62 \mathrm{~mm}$,

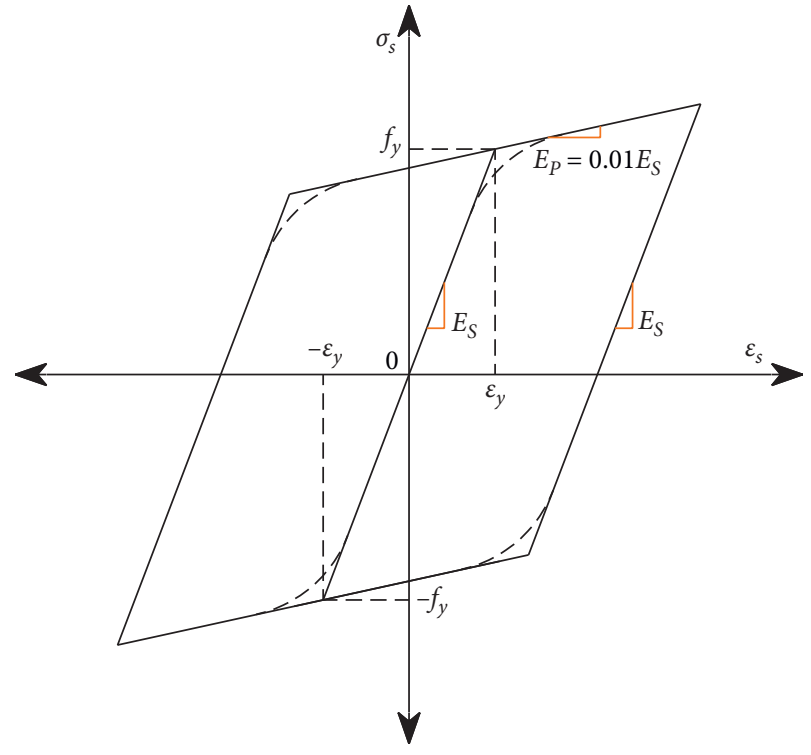

FiguRE 7: Stress-strain relationship of steel.

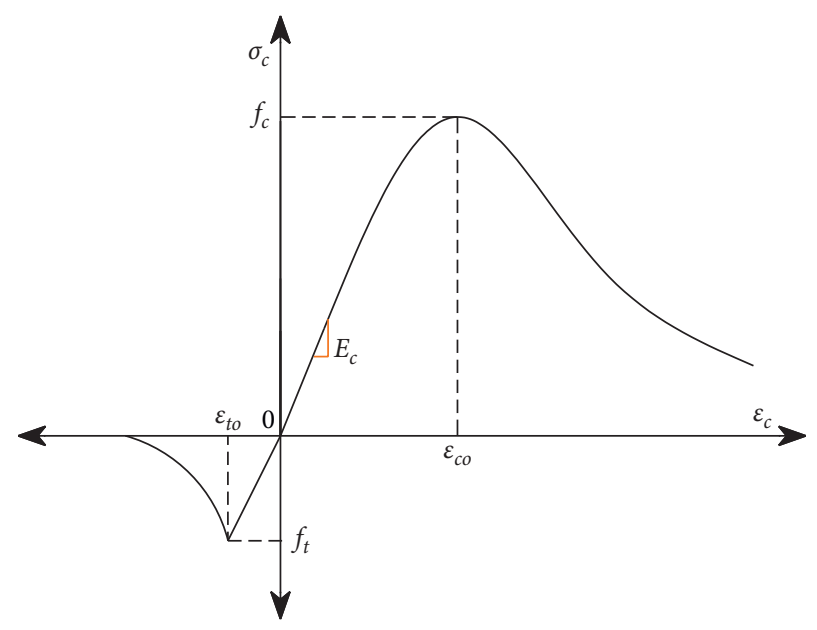

FIgURE 8: Stress-strain relationship of concrete.

respectively. It can be seen from Figure 14(d) that the bearing capacity increased with increasing the structural height. When the clearance increases from $22 \mathrm{~mm}$ to $42 \mathrm{~mm}, 62 \mathrm{~mm}$, the bearing capacity of the COF system in the positive direction is found to increase by $4.9 \%$ and $11.2 \%$, respectively; the bearing capacity of the COF system in the negative direction is found to increase by $12.5 \%$ and $14.3 \%$, respectively.

4.5. Stiffness Degradation. The stiffness degeneration of a structure with respect to the increment in the displacement is an important index for assessing the structural seismic performance [25]. For the COF system studied in this paper, the structural response is inconsistent in the positive and negative directions. Hence, stiffness degradation in two directions needs to be analyzed. The stiffness degradation coefficient $K$ can be used to evaluate the degeneration of the structural stiffness [4], which can be expressed as 


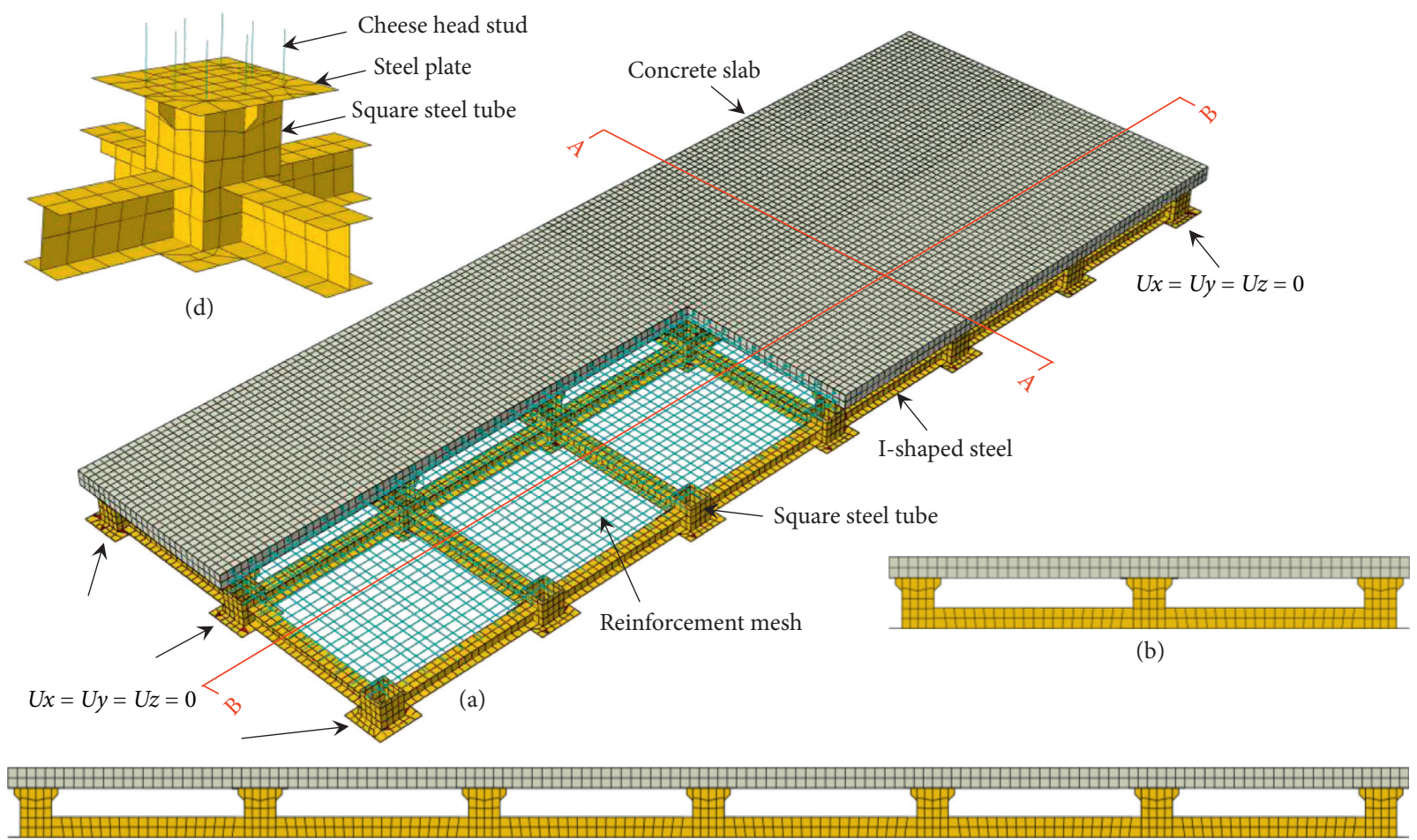

(c)

Figure 9: FE meshes of the COF system. (a) Meshed FE model. (b) A-A section. (c) B-B section. (d) Details of joint.

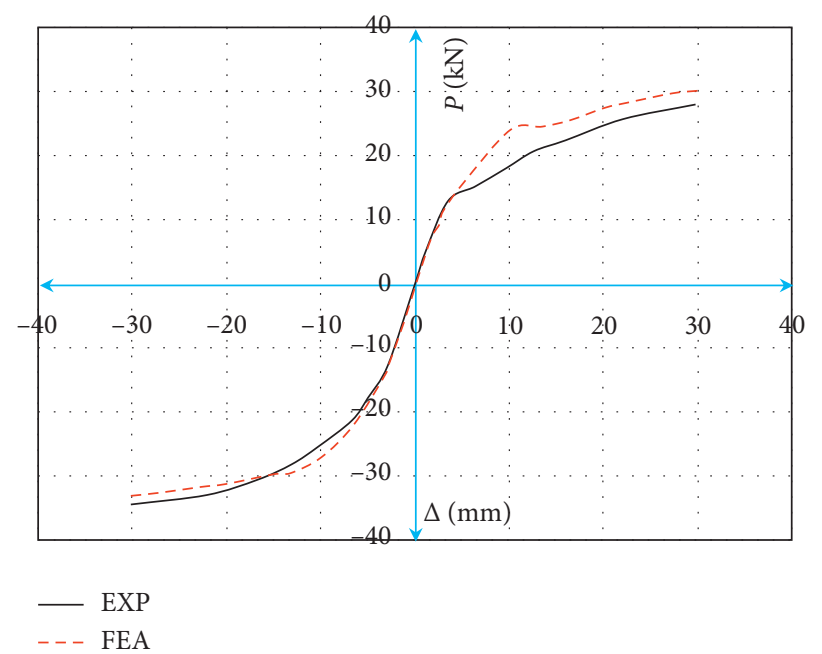

FIGURE 10: Comparison of skeleton curves.

$$
K_{i}=\frac{\sum_{j=1}^{n} P_{i, j}}{\sum_{j=1}^{n} \Delta_{i, j}},
$$

where $P_{i, j}$ and $\Delta_{i, j}$ are the peak bearing capacity and the corresponding displacement of the $j$ th cycle at the $i$ th loading level, respectively.

Figure 15 shows the comparison on the stiffness degradation of different COF systems; the following conclusions can be drawn from Figure 15:
The initial stiffness of the COF system in the positive direction is larger than that of the $\mathrm{COF}$ structure in the negative direction.

The concrete grade of the top slab makes little effect on the stiffness degradation of the COF system; only a slight difference is observed in the small deformation stage.

The steel grade of section steels has an important influence on the stiffness degeneration of the COF 


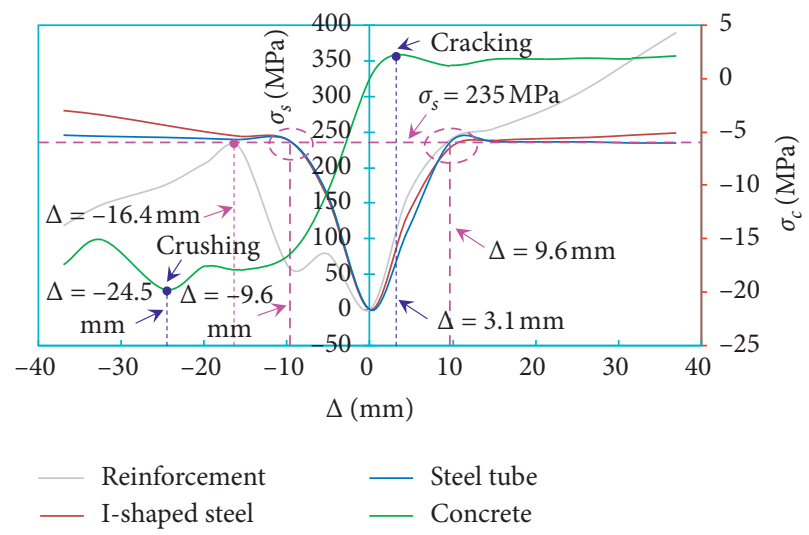

Figure 11: Stress development process of components.

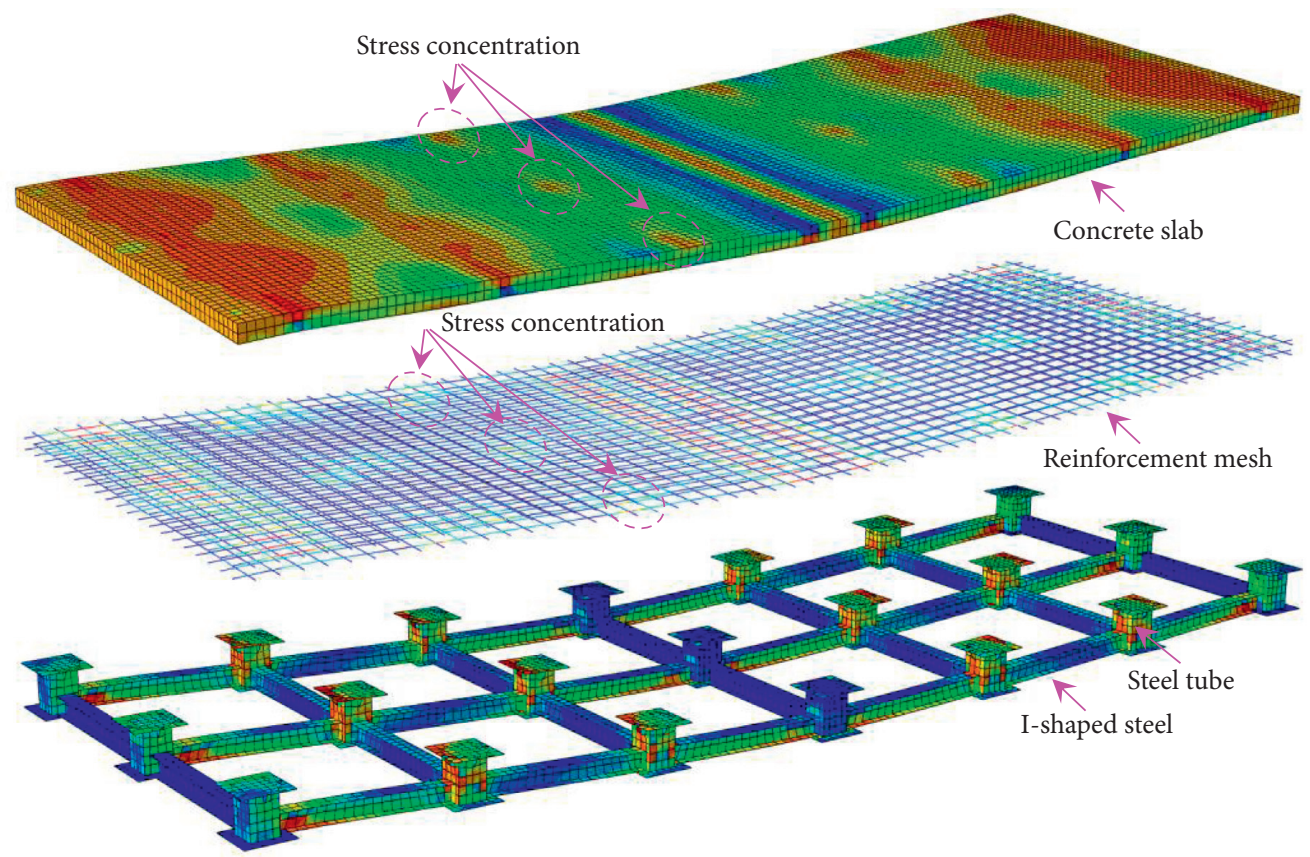

Figure 12: Stress states under vertical deflection of $-10.8 \mathrm{~mm}$.

system. Although the initial stiffness of the COF system with different steel grade is almost the same, the stiffness degeneration degree of the structure increased with the decrease of steel strength.

The influence of the thickness of section steels on the stiffness degeneration of the COF system is most remarkable. The smaller the thickness of the section steel is, the weaker the structural initial stiffness is. Further, more significant stiffness degeneration was observed in the COF system with thicker section steels.

For COF systems with different structural heights, the initial stiffness of the structure increased with the increase of structural height. Nevertheless, the stiffness degeneration degree of COF systems with different structural heights is similar.
4.6. Energy Dissipation. The energy dissipation capacity of a structure is also an important index to evaluate the seismic performance of the structure. The energy dissipation $E$ can be defined by the area of hysteretic loops. In order to quantify the energy dissipation of the COF system, the accumulated dissipated energy of all analyzed models was calculated, as illustrated in Figure 16. The following observations can be drawn:

The concrete strength of the top slab makes little influence on the energy dissipation of the COF system, as illustrated in Figure 16(a). When the strength of the applied concrete increased, the energy dissipation ability of the COF system is improved slightly. Taking the displacements of $\pm 32.4 \mathrm{~mm}$ as the failure displacements of the structure, the failure displacements 


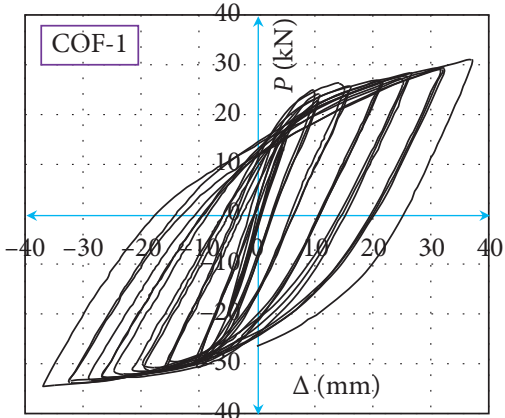

(a)

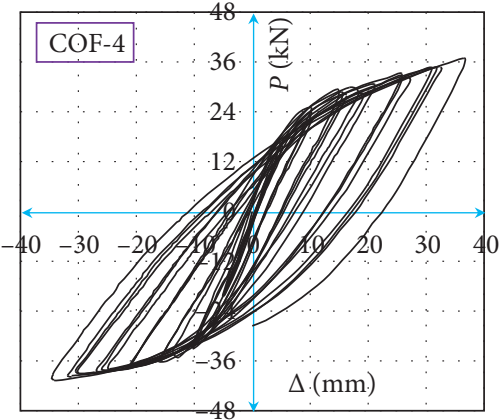

(d)

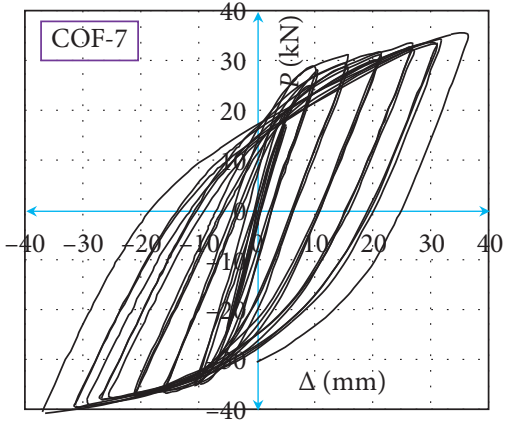

(g)

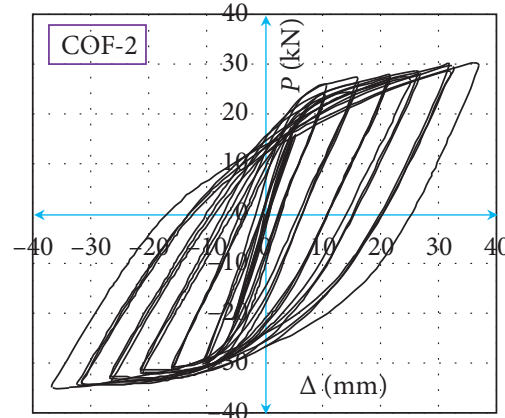

(b)

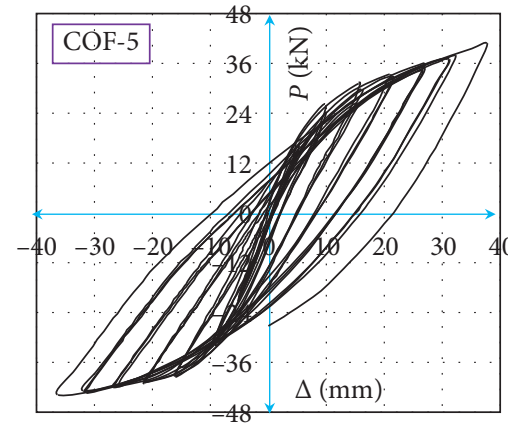

(e)

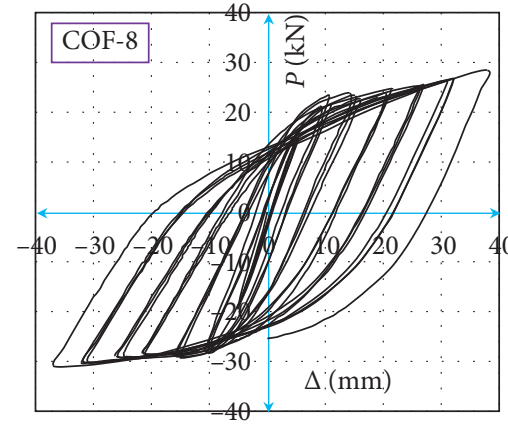

(h)

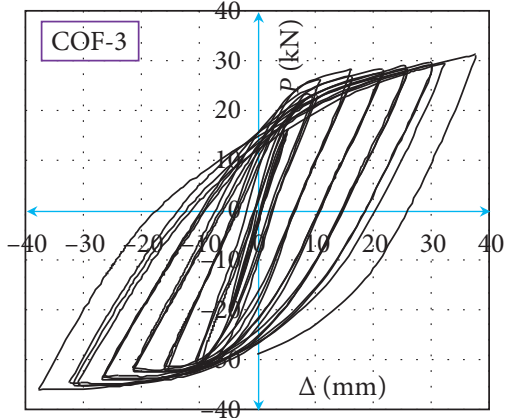

(c)

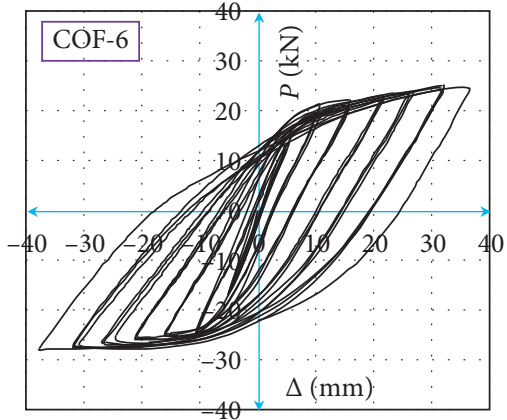

(f)

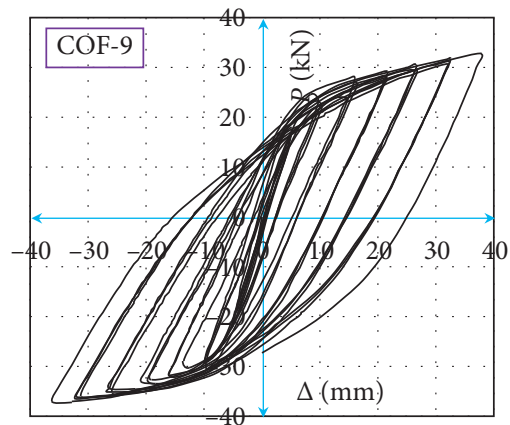

(i)

Figure 13: $P-\Delta$ hysteretic curves.

are about $1 / 66$ of the structural span length. When the concrete strength of the top slab increases from $20.1 \mathrm{MPa}$ to $23.4 \mathrm{MPa}, 26.8 \mathrm{MPa}$, the accumulated dissipated energy of the COF system at failure is found to increase by $7.2 \%$ and $8.2 \%$, respectively.

For section steels with different steel grades, the comparisons of the accumulated dissipated energy of COF systems were given in Figure 16(b). It can be found that the steel grade of section steels has an important influence on the accumulated dissipated energy of the COF system. The accumulated dissipated energy of the structure decreased with increasing the steel strength at the same displacement level. When the steel strength of section steels increases from $235 \mathrm{MPa}$ to $345 \mathrm{MPa}$, $420 \mathrm{MPa}$, the accumulated dissipated energy of the COF system at failure is found to decrease by $13.8 \%$ and $25.3 \%$, respectively. A possible reason for these changes is that the plastic development of high-strength steel is relatively small during the loading process. Hence, the COF system with high-strength section steels showed a low accumulated dissipated energy.

The most remarkable effect on the accumulated dissipated energy of the COF system was the thickness of section steels, as illustrated in Figure 16(c). When the section steel thickness increased, the energy dissipation ability of the COF system is improved significantly. When the thickness of section steels increases from $1.5 \mathrm{~mm}$ to $2.0 \mathrm{~mm}, 2.5 \mathrm{~mm}$, the accumulated dissipated energy of the COF system at failure is found to increase by $15.1 \%$ and $32.3 \%$, respectively. The reason for this 


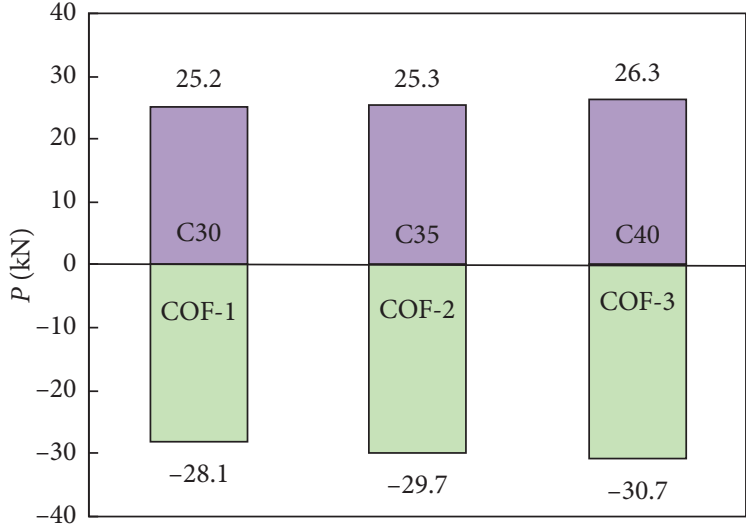

(a)

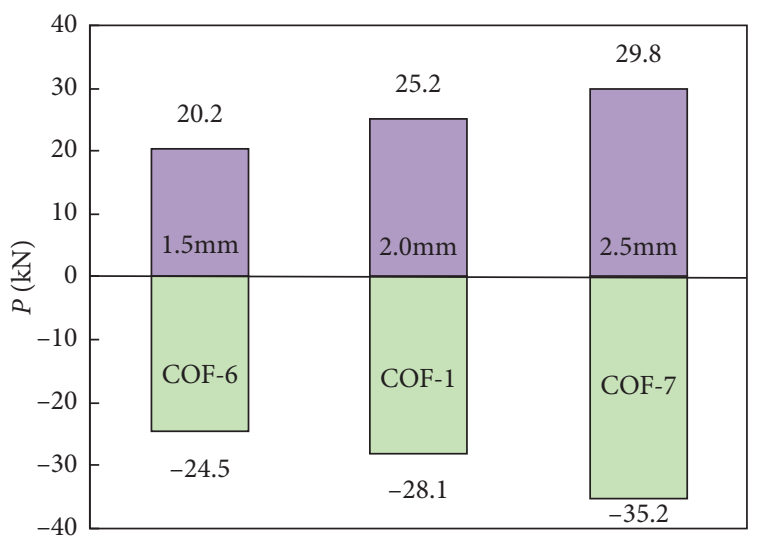

(c)

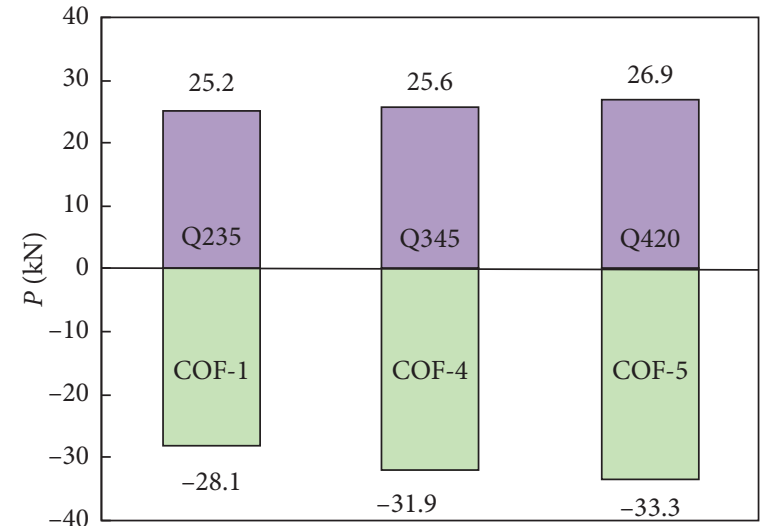

(b)

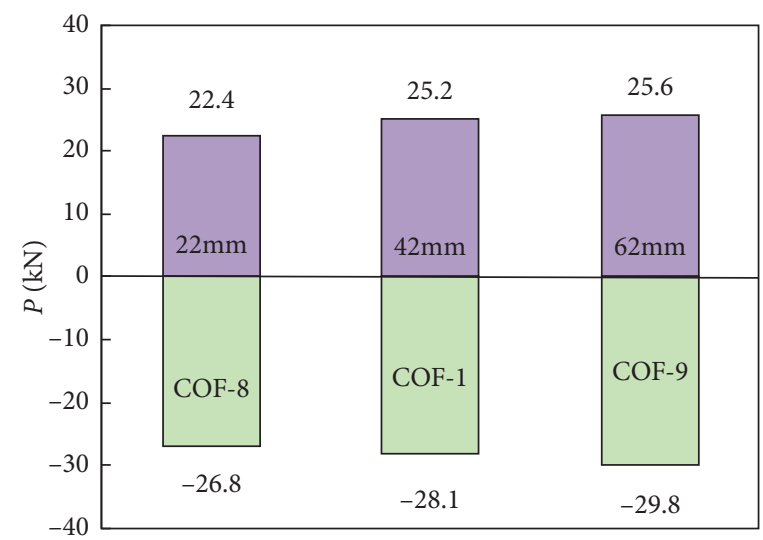

(d)

FIgURE 14: Comparison on bearing capacity of COF system.
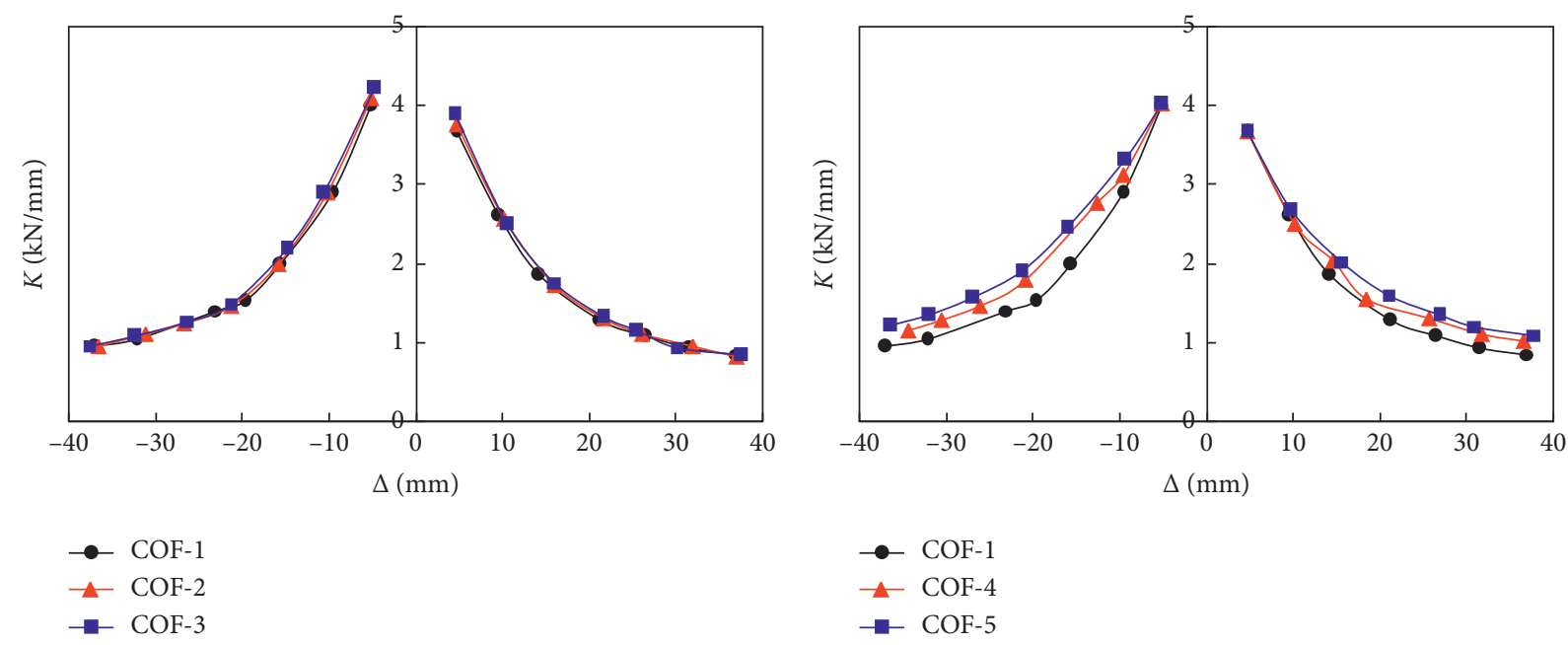

(a)

(b)

FIgURE 15: Continued. 


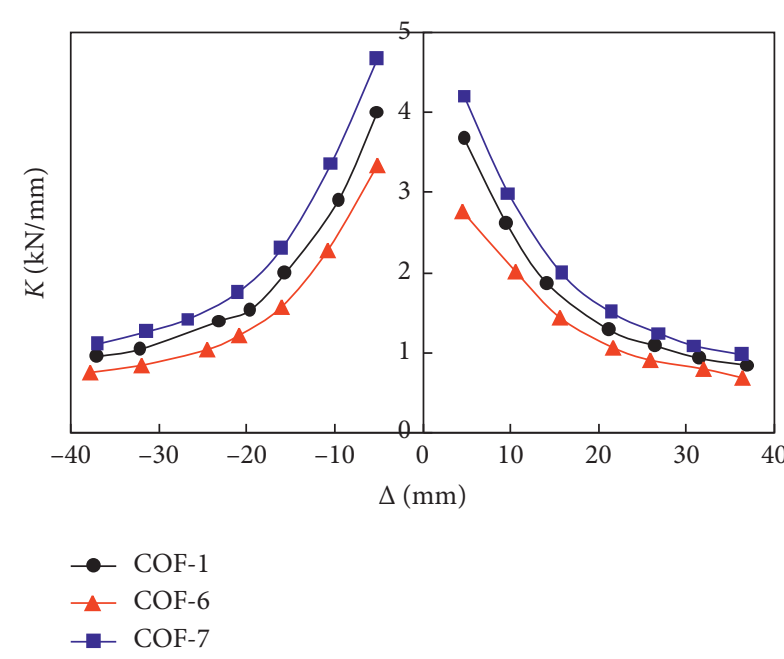

(c)

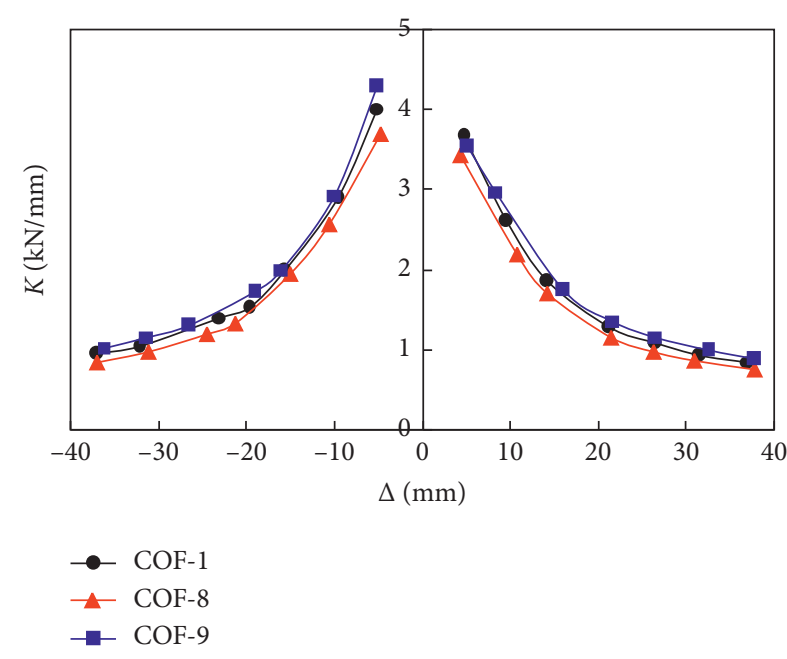

(d)

Figure 15: Comparison on stiffness degradation of COF system.

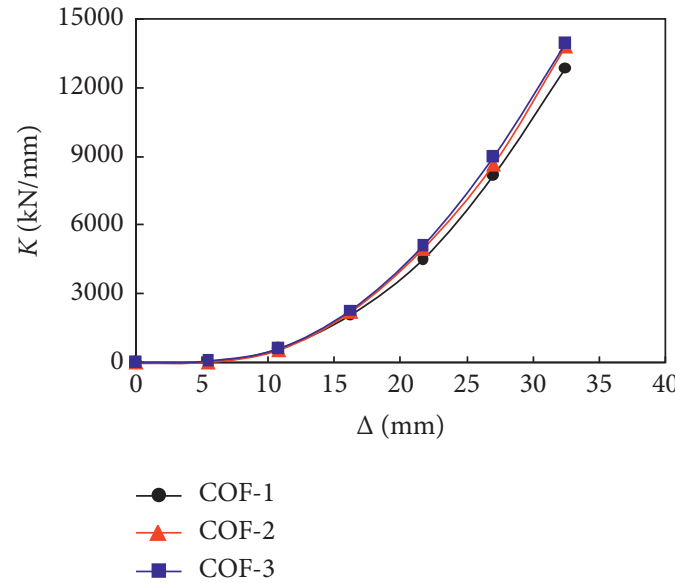

(a)

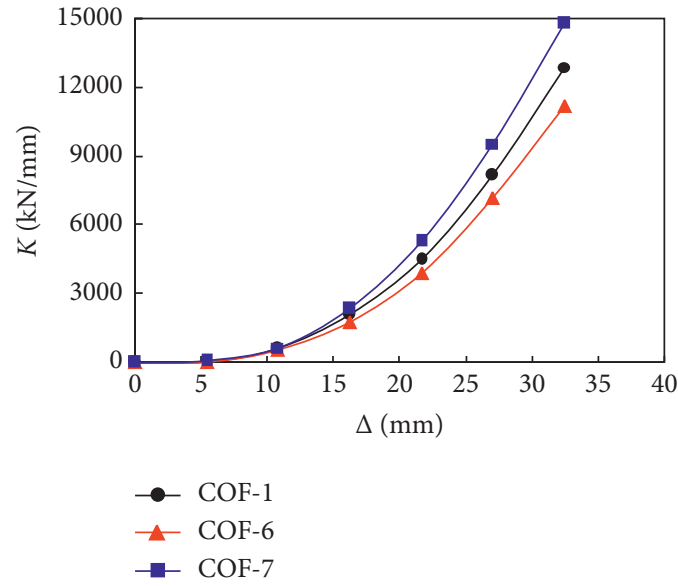

(c)

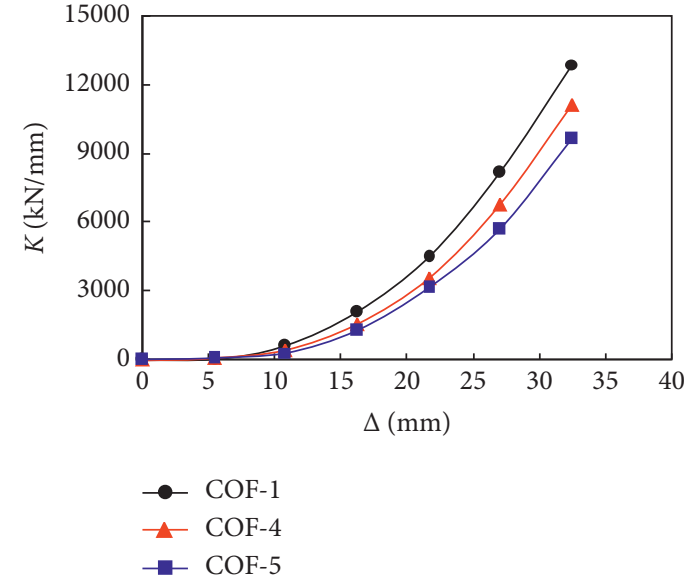

(b)

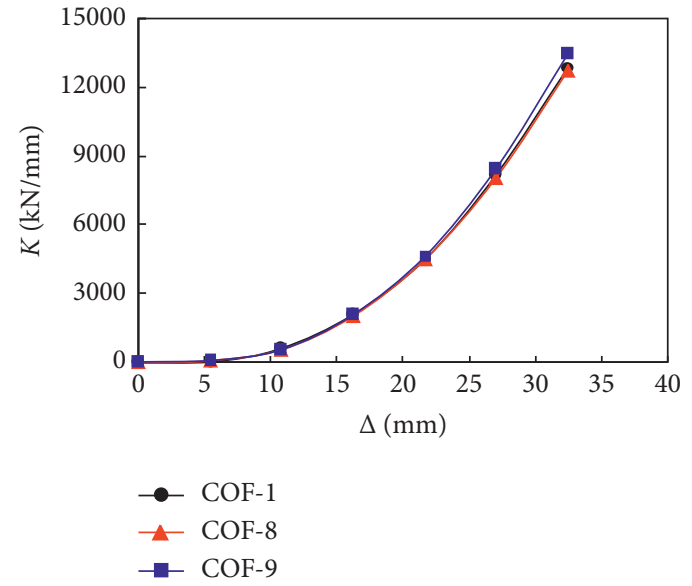

(d)

Figure 16: Comparison on energy dissipation of COF system. 
change is that the COF system with thicker section steels has higher bearing capacity, resulting in a largerarea hysteretic loop. Hence, the energy dissipation ability of the COF system is also relatively stronger.

Figure 16(d) shows the accumulated dissipated energy of COF systems with different structural heights. From the figure, it can be seen that the accumulated dissipated energy is almost the same during the loading process, especially in the early stage of loading. Only a slight difference is observed in the later stage of loading. When the structural height increases from $90 \mathrm{~mm}$ to $110 \mathrm{~mm}, 130 \mathrm{~mm}$, the accumulated dissipated energy of the COF system at failure is found to increase by $1.0 \%$ and $5.6 \%$, respectively. Hence, the structural height has little influence on the energy dissipation.

\section{Summary and Conclusions}

In this paper, the seismic behavior of a composite largespan open-web floor system consisting of I-shaped steel chords and steel tube webs (COF) was investigated through experimental study and FE modeling. The effects of the concrete strength, steel strength, thickness of section steels, and structural height were studied. According to the test results and numerical analysis, the research findings obtained may be summarized within the limitation of the study:

(1) Based on the test results of the COF specimen, the bending damage of the concrete slab and slip between steel tube webs and concrete slab led to the failure of the specimen. As a whole, the measured load-displacement hysteretic curves of the specimen are comparatively plump and full, which indicated that the COF system has a good seismic behavior.

(2) The effects of the steel strength, section steel thickness, and structural height on the load-displacement hysteretic curve are proved to be significant. However, the comparison of COF systems with different concrete strength indicated that an increase in concrete strength caused no significant change in hysteretic curves.

(3) The bearing capacities of COF systems in the positive direction are generally greater than those in the negative direction. Increasing the concrete strength, steel strength, section steel thickness, and structural height can lead to an increase in the bearing capacity of structures without exception. Among them, the most significant impact parameter is the thickness of section steels.

(4) The study of the stiffness degradation of COF systems shows that the concrete strength and structural height have no significant impact on the stiffness degradation of the structure. However, the influence of the steel strength and section steel thickness on the stiffness degeneration of the COF system is most remarkable.

(5) The concrete strength and structural height make little impact on the energy dissipation of the COF system.
Nevertheless, the influence of the steel strength and section steel thickness on the energy dissipation is remarkable; the accumulated dissipated energy of the COF system decreased with increasing the steel strength and increased with increasing the thickness of section steels. When the steel strength increases from $235 \mathrm{MPa}$ to $420 \mathrm{MPa}$, the accumulated dissipated energy is found to decrease by $25.3 \%$. When the section steel thickness increases from $1.5 \mathrm{~mm}$ to $2.5 \mathrm{~mm}$, the accumulated dissipated energy is found to increase by $32.3 \%$.

Although the scaled model of the COF system has been tested, the size of the sample prepared for the test is relatively small, and the number of the tested specimens is not high enough; this may lead to the deviation of the research results. For subsequent studies of the COF system, more influence factors should be considered in experimental programs, such as the dimensions of the test specimens, the connection types of the structures, and the supporting conditions of the COF system.

\section{Data Availability}

The data used to support the findings of this study are included within the article.

\section{Additional Points}

An experimental study was conducted to investigate the seismic behavior of the COF system. A finite element analysis model was developed to simulate the seismic performance of the COF system. A parametric study was conducted to investigate the influence on seismic behavior.

\section{Conflicts of Interest}

The authors declare that they have no conflicts of interest regarding the publication of this paper.

\section{Acknowledgments}

The authors gratefully acknowledge the financial support provided by the National Natural Science Foundation of China (Grant no. 52068007), the Science and Technology Foundation of Guizhou Province (Grant no. QKHJC[2020] 1Y417), and the Research Project of Introducing Talents in Guizhou University (Grant no. GDRJHZ[2019]08).

\section{References}

[1] L. H. Han, W. Li, and R. Bjorhovde, "Developments and advanced applications of concrete-filled steel tubular (CFST) structures: Members," Journal of Constructional Steel Research, vol. 100, pp. 211-228, 2014.

[2] S. El-Tawil and G. G. Deierlein, "Strength and ductility of concrete encased composite columns," Journal of Structural Engineering, vol. 125, no. 9, pp. 1009-1019, 1999.

[3] L. Zhou and Y. S. Su, "Cyclic loading test on beam-to-column connections connecting SRRAC beams to RACFST columns," International Journal of Civil Engineering, vol. 16, no. 11, pp. 1533-1548, 2018. 
[4] L. Zhou and Y. S. Su, "Experimental study on seismic behavior of SRC deep beam-to-CFST column frames," Journal of Constructional Steel Research, vol. 155, pp. pp157-175, 2019.

[5] M. J. Bandelt, S. P. Gross, D. W. Dinehart, J. R. Yost, and J. D. Pudleiner, "Flexural behavior of a composite steel and precast concrete open web dissymmetric framing system," Engineering Structures, vol. 198, Article ID 109456, 2019.

[6] A. Brattland and D. J. L. Kennedy, "Flexural tests of two fullscale composite trusses," Canadian Journal of Civil Engineering, vol. 19, no. 2, pp. 279-295, 1992.

[7] Y. Huang, D. J. Du, X. Yang, and Y. Jin, "Design and field test research of large span and heavy load steel-concrete composite open-web floor," in Proceedings of the Fourth International Conference on Advances in Steel Structures, vol. 2, pp. 1299-1304, SHG, China, June 2005.

[8] G. Merryfield, A. El-Ragaby, and F. Ghrib, "New shear connector for open web steel joist with metal deck and concrete slab floor system," Construction and Building Materials, vol. 125, pp. 1-11, 2016.

[9] H. Luan, K. Ma, Y. Qin, Z. Chen, and Y. Wei, "Investigation of the structural behavior of an innovative steel open-web floor system," International Journal of Steel Structures, vol. 17, no. 4, pp. 1365-1378, 2017.

[10] Y. Yang, R. Liu, X. Huo, X. Zhou, and C. W. Roeder, "Static experiment on mechanical behavior of innovative flat steel plate-concrete composite slabs," International Journal of Steel Structures, vol. 18, no. 2, pp. 473-485, 2018.

[11] L. S. Luo and X. F. Zhang, "Flexural response of steel-concrete composite truss beams," Advances in Civil Engineering, vol. 2019, Article ID 1502707, 15 pages, 2019.

[12] M. Kożuch and W. Lorenc, "The behaviour of clothoidshaped composite dowels: experimental and numerical investigations," Journal of Constructional Steel Research, vol. 167, Article ID 105962, 2020.

[13] W. Lorenc, "Concrete failure of composite dowels under cyclic loading during full-scale tests of beams for the "Wierna Rzeka" bridge," Engineering Structures, vol. 209, Article ID 110199, 2020.

[14] X. Zhang, Q. M. Wang, Y. Wang, and Q. Li, "Experimental and analytical study on the vibration performance of U-shaped steel-concrete composite hollow waffle slab," Shock and Vibration, vol. 2020, Article ID 1928075, 15 pages, 2020.

[15] S. K. Kunnath, E. Erduran, Y. H. Chai, and M. Yashinsky, "Effect of near-fault vertical ground motions on seismic response of highway overcrossings," Journal of Bridge Engineering, vol. 13, pp. 282-290, 2008.

[16] W. Z. Xu, D. S. Du, S. G. Wang, and W. Q. Liu, "Shaking table tests on the multi-dimensional seismic response of long-span grid structure with base-isolation," Engineering Structures, vol. 201, Article ID 109802, 2019.

[17] A. Kalantari and S. A. Moayyedi, "Seismic vertical component effects on seismic demands of a base isolated bridge with friction-rubber bearings," Civil Engineering Research Journal, vol. 3, Article ID 555617, 2018.

[18] Ministry of housing and urban rural development of the people's republic of China, GB/T 228-2002 Metallic Materials-Tensile Testing At Ambient Temperature, Standards Press of China, Beijing, China, 2002.

[19] Ministry of Housing and Urban Rural Development of the People's Republic of China, GB/T 50081-2016 Standard For Test Method Of Mechanical Properties On Ordinary Concrete, China Architecture \& Building Press, Beijing, China, 2016.
[20] American Iron and Steel Institute, ATC-24 Guidelines for Cyclic Seismic Testing of Components of Steel Structures, Applied Technology Council, Redwood City, USA, 1992.

[21] Abaqus, Analysis User's Manual, Version 6.14, Hibbitt, Karlsson and Sorensen, USA, 2014.

[22] N. H. Nguyen and A. S. Whittaker, "Numerical modelling of steel-plate concrete composite shear walls," Engineering Structures, vol. 150, pp. 1-11, 2017.

[23] M. Lasheen, A. Shaat, and A. Khalil, "Numerical evaluation for the effective slab width of steel-concrete composite beams," Journal of Constructional Steel Research, vol. 148, pp. 124-137, 2018.

[24] Ministry of Housing and Urban Rural Development of the People's Republic of China, GB 50010-2010 Code For Design of Concrete Structures, China Architecture \& Building Press, Beijing, China, 2010.

[25] L. Zhou and Y. S. Su, "Experimental and numerical studies on seismic behavior of composite frames with initial heavy load conditions," Iranian Journal of Science and Technology, Transactions of Civil Engineering, vol. 44, no. 2, pp. 533-547, 2020. 